\title{
Experimental infection of self-cured Leiopelma archeyi with the amphibian chytrid Batrachochytrium dendrobatidis
}

\author{
Stephanie D. Shaw ${ }^{1, *}$, Phillip J. Bishop ${ }^{2}$, Lee Berger ${ }^{1}$, Lee Francis Skerratt ${ }^{1}$, \\ Stephen Garland ${ }^{1}$, Dianne M. Gleeson ${ }^{3}$, Amanda Haigh ${ }^{4}$, Sarah Herbert ${ }^{2}$, Rick Speare ${ }^{1}$ \\ ${ }^{1}$ Amphibian Disease Ecology Group, School of Public Health, Tropical Medicine and Rehabilitation Sciences, \\ James Cook University, Townsville, Queensland 4811, Australia \\ ${ }^{2}$ Department of Zoology, University of Otago, PO Box 56, Dunedin 9054, New Zealand \\ ${ }^{3}$ Landcare Research Ltd, Private Bag 92170, Auckland, New Zealand \\ ${ }^{4}$ Waikato Conservancy Office, Department of Conservation, Private Bag 3072, Hamilton, New Zealand
}

\begin{abstract}
The susceptibility of Archey's frog Leiopelma archeyi to Batrachochytrium dendrobatidis $(B d)$ is unknown, although one large population is thought to have declined sharply due to chytridiomycosis. As primary infection experiments were not permitted in this endangered New Zealand species, 6 wild-caught $L$. archeyi that naturally cleared infections with $B d$ while in captivity were exposed again to $B d$ to assess their immunity. These frogs were from an infected population at Whareorino, which has no known declines. All 6 L. archeyi became reinfected at low intensities, but rapidly self cured, most by 2 wk. Six Litoria ewingii were used as positive controls and developed heavier infections and clinical signs by $3 \mathrm{wk}$, demonstrating that the zoospore inoculum was virulent. Six negative controls of each species remained uninfected and healthy. Our results show that $L$. archeyi that have self cured have resistance to chytridiomycosis when exposed. The pattern is consistent with innate or acquired immunity to $B d$, and immunological studies are needed to confirm this.
\end{abstract}

KEY WORDS: Leiopelma archeyi $\cdot$ Litoria ewingii $\cdot$ Batrachochytrium dendrobatidis $\cdot$ Chytridiomycosis

Resale or republication not permitted without written consent of the publisher

\section{INTRODUCTION}

New Zealand has 7 extant species of frogs. The 4 native species are Leiopelma archeyi, L. hamiltoni, L. hochstetteri and L. pakeka. Leiopelmatids are an archaic family of anurans with many unique features such as vestigial tail-wagging muscles, cartilaginous inscriptional ribs, the presence of amphicoelous vertebrae and 9 presacral vertebrae (Bishop et al. 2008). They are all direct developers; L. hochstetteri is nidicolous while the others are exoviviparous with the hatchlings completing development on the male's dorsum (Bell \& Wassersug 2003). All 4 species are on the top 60 Evolutionarily Distinct and Globally Endangered (EDGE) amphibian list, with $L$. archeyi in the No. 1 position (www.edgeofexistence.org). In addition, all are nationally threatened, with $L$. archeyi classified as endangered (Hitchmough et al. 2005). L. archeyi has 2 geographically distinct populations; L. hamiltoni and L. pakeka have just one naturally occurring population each and L. hochstetteri has over 10 distinct populations (Bishop et al. 2008). Litoria aurea, L. ewingii and $L$. raniformis were introduced from Australia over 100 yr ago, and in their country of origin all 3 are on the IUCN red list (www.iucnredlist.org).

In 1999, Batrachochytrium dendrobatidis $(B d)$ was found in New Zealand in dying Litoria raniformis in a pond near Christchurch (Waldman et al. 2001). It is now known to be widespread in New Zealand and has been found in all Litoria species and Leiopelma archeyi (Bell et al. 2004, Shaw et al. 2008a). Limited testing did not detect infections in L. hochstetteri, L. 
pakeka (Shaw et al. 2008a) and L. hamiltoni (P. Bishop unpubl. data). Chytridiomycosis has spread worldwide, causing massive die-offs leading to amphibian population declines and extinctions (Skerratt et al. 2007, Padgett-Flohr \& Hopkins 2009). However, its past and potential impacts on New Zealand's unique amphibians, and its time of arrival, are unknown.

In 2001, chytridiomycosis was discovered in one dead Leiopelma archeyi in the Coromandel Peninsula following a sharp population decline in 1995 (Bell et al. 2004). As other potential causes for the declines in $L$. archeyi such as predation, habitat loss and poisons were ruled out, the introduction of $B d$ was suggested as the most likely cause (Bell et al. 2004). In 2005, chytridiomycosis was detected in the only other population of $L$. archeyi. Since this population in the Whareorino forest had not appeared to have declined (although long-term studies had not been conducted), there was concern the disease had just arrived, so an emergency translocation was initiated (Haigh et al. 2007). Twelve of $100 \mathrm{~L}$. archeyi captured for the translocation that tested positive for $B d$ during a $90 \mathrm{~d}$ quarantine period were transferred to the University of Otago for use in a treatment trial. However, when retested at the research facility, all except one frog had self cured. The last frog also became negative after a short course of topical chloramphenicol (Bishop et al. 2009). In addition to this unexpected self cure in captive frogs held at conditions ideal for $B d$, the prevalence of $B d$ in the Whareorino population increased over the next $3 \mathrm{yr}$, but the abundance of frogs did not appear to decline (Shaw et al. 2008a). Therefore, the question arises as to why there was a population decline in $L$. archeyi on the Coromandel peninsula, but not in the Whareorino, as they have a similar habitat, altitude and climate. One hypothesis is that $B d$ arrived at Whareorino before the population was monitored, and the disease is now in a stable endemic phase. Small stable remnant populations after initial large declines have been reported in a few Australian species, such as Taudactylus eungellensis (Retallick et al. 2004), and some species have recovered some of their previous distribution and abundance, such as Litoria genimaculata (McDonald et al. 2005). This may also have occurred in L. archeyi in the Coromandel (Shaw et al. 2008a). An alternate hypothesis is that $L$. archeyi are innately resistant to $B d$ and the population crash in the Coromandel was caused by an undetermined unrelated factor or co-factor that makes $L$. archeyi susceptible to $B d$.

Little is known about immunity to $B d$ in amphibians, although there is great variability in susceptibility among species and individuals, with some species undergoing no mortality (Berger et al. 2009). Some species of amphibians can clear infection at high tem- peratures, and there is variable pathogenicity among fungal strains (Berger et al. 2004). Mechanisms of resistance that are under investigation include aspects of innate immunity, such as dermal antimicrobial peptides and resident bacterial flora (Rollins-Smith \& Conlon 2005, Woodhams et al. 2006, Harris et al. 2009). The acquired immune response to $B d$ has not been described.

This study aimed to test the following: (1) whether Leiopelma archeyi that self cured their naturally acquired infection with $B d$ could be reinfected by experimental challenge with $B d_{i}(2)$ whether reinfected $L$. archeyi developed clinical signs of chytridiomycosis; and (3) whether reinfected $L$. archeyi could again self cure. Information on the susceptibility of $L$. archeyi is clearly needed to determine the threats to, and to plan management of, this critically endangered species.

\section{MATERIALS AND METHODS}

The 12 Leiopelma archeyi used in this experiment (6 controls, 6 to be exposed) were wild caught in the Whareorino forest in the Waikato Region of New Zealand (ca. $38^{\circ} \mathrm{S}, 174^{\circ} \mathrm{E}$ ) in September 2006 and quarantined for $90 \mathrm{~d}$ at Hamilton Zoo (Bishop et al. 2009). All had $3 B d$ PCR tests done 14 d apart in September and October 2006 (Haigh et al. 2007). They were retested upon arrival at the University of Otago in December 2006 and many times thereafter. Eleven of the 12 frogs had 7 negative tests in a row over $19 \mathrm{wk}$. The last frog had 6 negative tests in a row, as the first test upon arrival was positive (Bishop et al. 2009). The 12 Litoria ewingii used as positive and negative controls were wild-caught from Macraes Flat in the Otago Region of New Zealand $\left(45^{\circ} 22^{\prime} \mathrm{S}, 170^{\circ} 25^{\prime} \mathrm{E}\right)$ up to 12 mo before the experiment. L. ewingii is known to be susceptible to chytridiomycosis (Berger et al. 2004). It is similar in size to $L$. archeyi and hence provides a surface area that is valid for comparison of zoospore equivalents on PCR. All frogs were given a physical examination by a veterinarian and were negative by $B d$ PCR prior to the experiment. Upon entering the study, one $L$. archeyi positive control had nodular skin lesions that were thought to be adenomas (Shaw et al. 2008c). Since these lesions have been seen on numerous $L$. archeyi and are not known to cause morbidity (Shaw \& Holzapfel 2008), the frog was retained in the experiment.

Frogs were housed individually in semi-transparent plastic containers $(310 \times 210 \times 90 \mathrm{~mm})$ on 3 paper towels moistened with aged filtered water and changed weekly. The containers were housed on 2 shelving units in an isolated refrigerated room kept at $15^{\circ} \mathrm{C}$ and 
close to $100 \%$ humidity. This is similar to the average maximum temperature of the natural habitat of Leiopelma archeyi, which is $15.2^{\circ} \mathrm{C}$ (Eggers 1998). One shelving unit held L. archeyi and the other held Litoria ewingii, with the positive and negative controls on different shelves. Strict hygiene practices were used to avoid cross-contamination by servicing negative controls first and using new nitrile gloves for each frog. Frogs were weekly fed a varying diet of laboratorycultured insects consisting of waxmoth larvae Galleria, fruit flies Drosophila, small black crickets Teleogryllus commodus and house flies Mus musca.

As a New Zealand isolate of $B d$ was not available, a culture of type isolate JEL 197 (Longcore et al. 1999) was sourced from a cryo-archived culture (Boyle et al. 2003) held at the Department of Biochemistry, University of Otago, by R. Poulter and M. Butler; it had been passaged on $1 \%$ tryptone plates at $23^{\circ} \mathrm{C}$ for about $1 \mathrm{yr}$ prior to this experiment. Zoospores were collected from $4 \mathrm{~d}$ old cultures on $1 \%$ tryptone agar plates held at $23^{\circ} \mathrm{C}$ by flooding with $6 \mathrm{ml}$ of dilute salt solution (DSS, imitating pond water; Boyle et al. 2004). The number of live zoospores present in the DSS was determined using a haemocytometer. The 6 Leiopelma archeyi to be exposed and the 6 positive control Litoria ewingii were each exposed to approximately 250000 zoospores (within $30 \mathrm{~min}$ of zoospore collection) in $10 \mathrm{ml}$ DSS in $100 \times 130 \mathrm{~mm}$ plastic bags with a ziplock seal for $4 \mathrm{~h}$ at $15^{\circ} \mathrm{C}$ (a temperature suitable for $B d$ ). The 12 negative controls had the same treatment but without $B d$ zoospores. The sealed plastic bags prevented the frogs from climbing out of the water. The frogs were then returned to their containers together with the remaining liquid from the plastic bags.

Exposed frogs were swabbed for PCR testing every $7 \mathrm{~d}$ for up to $12 \mathrm{wk}$ post exposure. Frogs were observed daily, and at the time of swabbing they were also weighed and examined for clinical signs of $B d$ such as erythema, lethargy, irregular posture, inappetance and neurological signs (Berger et al. 2005). Taqman quantitative PCR (qPCR) for Bd (Boyle et al. 2004) was performed on the swabs and run in triplicate for each sample at both James Cook University (JCU) and Landcare Research Ltd laboratories (LR) for the pre-data and Week 1 for all frogs, then the first $4 \mathrm{wk}$ for Leiopelma archeyi alone. This double testing was carried out to validate the results obtained at LR, where the assay had been recently established, against those obtained at JCU, a laboratory experienced in running the assay. There were no significant differences in results from both laboratories (data not shown). The ad- ditional $L$. archeyi swabs were all tested at JCU while the remaining Litoria ewingii swabs were all tested at LR for confirmation of continued infections. Two facilities were used for funding reasons. Results for a sample were only considered positive if all 3 qPCR reactions were positive. Inhibition of the PCR was tested using an Applied Biosystem TaqMan ${ }^{\circledR}$ Exogenous Internal Positive Control (EIPC) (Hyatt et al. 2007).

The Litoria ewingii positive controls were transferred to a treatment experiment at Week 4, when they began developing clinical signs of chytridiomycosis and were likely to die within days if left untreated (Berger et al. 1998).

These experiments were conducted under the following permits: animal ethics from the University of Otago (AEC 88/06) and James Cook University (A1315) and Department of Conservation High Impact permit (WK-19818-RES).

\section{RESULTS}

\section{Leiopelma archeyi}

At the end of Week 1, all exposed Leiopelma archeyi were positive with low zoospore equivalents of 2 to 915 per sample (Table 1). Bd was rapidly cleared as demonstrated by only 2 of the 6 exposed frogs testing positive at Week 2, and by Week 3 all PCR results were negative. At Week 4, 1 of the frogs that was positive at Week 2 returned a positive result with a low zoospore equivalent, but all frogs were negative when retested at Weeks 5, 6, 9 and 12. The 6 negative control $L$. archeyi were negative for $B d$ at Week 1 and remained negative.

Exposed frogs either gained or maintained their weight and did not show clinical signs of chytridiomycosis. However, one exposed frog that was negative from Week 2 did show clinical signs of illness (lethargy, decreased righting reflex, tremors) at Week 5. These signs were attributed to metabolic bone disease, as this

Table 1. Batrachochytrium dendrobatidis (Bd) infecting Leiopelma archeyi and Litoria ewingii. Percent frogs positive (Pos) for $B d$ after exposure and zoospore equivalents. Each group had 6 frogs. L. ewingii were removed from the trial at Week 4 and treated. ZE: zoospore equivalents (mean \pm SD of infected frogs)

\begin{tabular}{|lcccc|}
\hline \multirow{2}{*}{ Time } & \multicolumn{2}{c}{ Leiopeima archeyi } & \multicolumn{2}{c|}{ Litoria ewingii } \\
& Pos & ZE & Pos & ZE \\
\hline Day 0 & 0.00 & 0 & 0.00 & 0 \\
Week 1 & 100.00 & $186.7 \pm 362.9$ & 83.30 & $5821.7 \pm 4872.5$ \\
Week 2 & 33.30 & $75.5 \pm 102.5$ & 100.00 & $16544.5 \pm 15457.5$ \\
Week 3 & 0.00 & 0 & 100.00 & $8202.7 \pm 5608.6$ \\
Week 4 & 16.70 & 27 & 100.00 & $6964.62 \pm 6567.2$ \\
Week 5 & 0.00 & 0 & Not tested & \\
& & & & \\
\hline
\end{tabular}


was a problem in another institution holding Leiopelma archeyi (Shaw et al. 2008b). Due to the possibility that all $L$. archeyi were calcium deficient, coupled with the fact that these are critically endangered species, treatment with percutaneous calcium/Vitamin D3 preparation (Calcivet ${ }^{\circledR}$ ) every 4 to $7 \mathrm{~d}$ was initiated in all $L$. archeyi at Week 5. In addition, the sick frog received daily baths of $2.5 \%$ calcium gluconate and $7 \mathrm{~d}$ of $2 \%$ chloramphenicol baths for its antibacterial effects. Hyatt et al. (2007) recommended 3 consecutive negative results over a $14 \mathrm{~d}$ period to confirm a negative result. As this frog had been negative for $B d$ for 3 consecutive weeks, it is thought that the chloramphenicol treatment had no bearing on the subsequent negative tests.

\section{Litoria ewingii}

At Week 1 post exposure, all 6 exposed Litoria ewingii were infected, with zoospore equivalents per sample of 2200 to 14000 (Table 1). All developed clinical signs of chytridiomycosis (erythema, increased sloughing of skin and lethargy) by Week 3 post exposure, and all frogs were transferred to a treatment experiment at Week 4. The 6 unexposed $L$. ewingii (negative controls) returned negative $B d \mathrm{PCR}$ results at Week 1 and remained negative. One frog was euthanised at Week 6 due to accidental trauma, and 1 was treated with an ophthalmic preparation of chloramphenicol due to corneal prolapse at Week 3.

\section{DISCUSSION}

Leiopelma archeyi individuals that had self cured from natural infections of $B d$ (Bishop et al. 2009) were exposed to $B d$, became infected and quickly self cured. Self curing has been reported in 4 free-living Litoria pearsoniana, but all at higher temperatures (19.5 to $\left.27^{\circ} \mathrm{C}\right)$ than our laboratory experiment $\left(15^{\circ} \mathrm{C}_{i}\right.$ Murray et al. 2009), which may have aided in their recovery (Berger et al. 2004). The infection of all 6 L. ewingii with development of clinical signs demonstrated that the $B d$ isolate was capable of transmission and was virulent. The experimental conditions were validated, and the results support the observation that $L$. archeyi from the Whareorino population are resistant to $B d$ infection. The results also support the possibility that a non-specific innate immune response or a specific acquired immune response influences resistance to $B d$ in $L$. archeyi. Without data on anti- $B d$ antibodies or cellular immune responses to $B d$, only indirect evidence can be used to indicate whether immunity caused elimination of $B d$. More rapid clearing at rechallenge than with a primary exposure would support specific acquired immunity, but for these frogs the response to their initial infections with $B d$ is not known. Hence, the mechanism for the rapid elimination of $B d$ from these $L$. archeyi remains to be determined.

Our findings that frogs from Whareorino have resistance to $B d$ supports the field data showing that populations are not declining even though $B d$ is present and prevalence is increasing (Shaw et al. 2008a). However, many free-living Leiopelma archeyi have very low zoospore counts (Bishop et al. 2009). This could result in false negative tests in the field and underestimation of prevalence. We hypothesise that longitudinal monitoring of individuals in mark-recapture studies may show a repeating cycle of reinfection and elimination and varying levels of prevalence.

Knowing that Leiopelma archeyi from the Whareorino population do not usually become clinically ill and clear infections with $B d$ suggests that a population decline is less likely to be imminent. This information would give the New Zealand Native Frog Recovery Group more options for captive management. Currently all captive populations of $L$. archeyi are maintained indoors with strict hygiene controls aimed at excluding chytridiomycosis (Shaw \& Holzapfel 2008). Unsatisfactory breeding and a high prevalence of metabolic bone disease in captivity (Shaw et al. 2008b) have given rise to question the sole use of indoor enclosures. However, if $B d$ is a minimal threat to this species, outdoor enclosures previously thought too risky can be used.

As New Zealand strains of $B d$ had not been isolated, we used an American isolate that could differ in virulence from those present at Whareorino. Isolates from Litoria ewingii in New Zealand have recently been cultured and have been sequenced (R. Poulter unpubl. data, S. Shaw unpubl. data), but none have been isolated from Leiopelma spp. This experiment should be repeated with isolates from New Zealand and with individuals from the Coromandel population, incorporating assessments of cellular and acquired immune responses.

A population genetic study of Leiopelma archeyi should also be undertaken to determine the likelihood of a previous population decline in the Whareorino population. Differences in the levels of resistance between the 2 populations in conjunction with the results of the genetic studies would be used to identify whether factors that influence resistance are intrinsic to the frog or are site specific. A higher genetic diversity in the Whareorino population would support the hypothesis that factors specific to the Coromandel population reduced resistance causing the documented population decline. A subsequent finding of no difference in resistance between the 2 populations would 
suggest that factors extrinsic to the frog, such as increased pathogenicity of $B d$, presence of other pathogens, poisons or other site-specific influences and interactions caused the decline. Lower resistance in the Coromandel population would suggest intrinsic genetic differences that influence immunity or resistance in general. Alternatively, if there was a previous population decline at Whareorino, potentially caused by $B d$, this would suggest that there are no factors that reduce resistance that are specific to Coromandel, especially if there are no differences in resistance between the 2 populations. A subsequent finding of reduced levels of resistance at Coromandel would again suggest intrinsic genetic differences that influence immunity or resistance in general. The scenarios would require different revisions to management and research plans, revisions that would be urgent if highly pathogenic strains of other pathogens were implicated.

Acknowledgements. We acknowledge a grant to S.D.S. from JCU Graduate Research Scheme. We thank J. Germano and J. Oldman for animal care.

\section{LITERATURE CITED}

Bell BD, Wassersug RJ (2003) Anatomical features of Leiopelma embryos and larvae: implications for anuran evolution. J Morphol 256:160-170

Bell BD, Carver S, Mitchell NJ, Pledger S (2004) The recent decline of a New Zealand endemic: How and why did populations of Archey's frog Leiopelma archeyi crash over 1996-2001? Biol Conserv 120:189-199

- Berger L, Speare R, Daszak P, Green DE and others (1998) Chytridiomycosis causes amphibian mortality associated with population declines in the rain forests of Australia and Central America. Proc Natl Acad Sci USA 95: 9031-9036

Berger L, Speare R, Hines H, Marantelli G and others (2004) Effect of season and temperature on mortality in amphibians due to chytridiomycosis. Aust Vet J 82:434-439

Berger L, Marantelli G, Skerratt LF, Speare R (2005) Virulence of the amphibian chytrid fungus Batrachochytrium dendrobatidis varies with the strain. Dis Aquat Org 68: 47-50

Berger L, Longcore JE, Speare R, Hyatt AD, Skerratt LF (2009) Fungal diseases in amphibians. In: Heatwole $H_{\text {, }}$ Wilkinson JW (eds) Amphibian biology, Vol 8. Amphibian decline: disease, parasites, maladies, and pollution. Surrey Beatty \& Sons, Chipping Norton, p 2986-3052

Bishop PJ, Germano JM, Bell B (2008) Leiopelmatid frogs: the world's most archaic frogs. In: Stuart S, Hoffman M, Chanson J, Cox N, Berridge R, Ramani P, Young B (eds) Threatened amphibians of the world. Conservation International, Arlington, VA, p 71-72

Bishop PJ, Speare R, Poulter RTM, Butler MI and others (2009) Elimination of amphibian chytrid fungus Batrachochytrium dendrobatidis by Archey's frog Leiopelma archeyi. Dis Aquat Org 84:9-15

Boyle DG, Hyatt AD, Daszak P, Berger L and others (2003) Cryo-archiving of Batrachochytrium dendrobatidis and other chytridiomycetes. Dis Aquat Org 56:59-64

Boyle DG, Boyle DB, Olsen V, Morgan JAT, Hyatt AD (2004) Rapid quantitative detection of chytridiomycosis (Batrachochytrium dendrobatidis) in amphibian samples using real-time Taqman PCR assay. Dis Aquat Org 60:141-148 Eggers KE (1998) Morphology, ecology and development of leiopelmatid frogs (Leiopelma spp.), in Whareorino forest, New Zealand. MSc thesis, Massey University, Palmerston North

Haigh A, Shaw SD, Holzapfel A, Bishop P (2007) Emergency translocation as a response to the detection of $B d$ in a naive threatened population of Leiopelma archeyi in New Zealand. Partners in Reptile and Amphibian Conservation, Tempe, AZ

Harris RN, Brucker RM, Walke JB, Becker MH and others (2009) Skin microbes on frogs prevent morbidity and mortality caused by a lethal skin fungus. Int Soc Microb Ecol 3:818-824

Hitchmough R, Bull L, Cromarty P (2005) New Zealand threat classification system lists. Science and Technical Publishing. Department of Conservation, Wellington

Hyatt AD, Boyle DG, Olsen V, Boyle DB and others (2007) Diagnostic assays and sampling protocols for the detection of Batrachochytrium dendrobatidis. Dis Aquat Org 73: $175-192$

Longcore JE, Pessier AP, Nichols DK (1999) Batrachochytrium dendrobatidis gen. et sp. nov., a chytrid pathogenic to amphibians. Mycologia 91:219-227

McDonald KR, Méndez D, Müller R, Freeman AB, Speare R (2005) Decline in the prevalence of chytridiomycosis in upland frog populations in North Queensland, Australia. Pac Conserv Biol 11:114-120

Murray K, Skerratt LF, Speare R, McCallum H (2009) Impact and dynamics of disease in species threatened by the amphibian chytrid fungus, Batrachochytrium dendrobatidis. Conserv Biol 23:1242-1252

Padgett-Flohr GE, Hopkins RL II (2009) Batrachochytrium dendrobatidis, a novel pathogen approaching endemism in central California. J Wildl Dis 83:1-9

> Retallick RWR, McCallum H, Speare R (2004) Endemic infection of the amphibian chytrid fungus in a frog community post-decline. PLoS Biol 2:e351, doi:10.1371/journals.pbio. 0020351

Rollins-Smith LA, Conlon JM (2005) Antimicrobial peptide defenses against chytridiomycosis, an emerging infectious disease of amphibian populations. Dev Comp Immunol 29:589-598

Shaw SD, Holzapfel A (2008) Mortality of New Zealand native frogs in captivity. Science and Technical Publishing, Department of Conservation, Wellington

Shaw SD, Haigh A, Bishop P, Skerratt L, Speare R, Berger L, Bell B (2008a) Distribution and prevalence of Batrachochytrium dendrobatidis in New Zealand. Wildlife Disease Association, Australasian Section, Kioloa

Shaw SD, Speare R, Bishop P, Potter J, Jakob-Hoff R (2008b) Nutritional secondary hyperparathyroidism (metabolic bone disease) in captive Archey's frogs. Native Frog Recovery Group, Auckland

Shaw SD, Speare R, Harvey C, Alley M and others (2008c) Blister-like skin masses in Archey's frog. Native Frog Recovery Group, Auckland

Skerratt LF, Berger L, Speare R, Cashins S and others (2007) Spread of chytridiomycosis has caused the rapid global decline and extinction of frogs. EcoHealth 4:125-134

Waldman B, Van De Wolfshaar K, Andjic V, Klena JD, Bishop P, Norman R (2001) Chytridiomycosis and frog mortality in New Zealand. NZ J Zool 28:372

- Woodhams DC, Voyles J, Lips KR, Carey C, Rollins-Smith LA (2006) Predicted disease susceptibility in a Panamanian amphibian assemblage based on skin peptide defenses. J Wildl Dis 42:207-218 